Plonski's site index curves for jack pine with a height of 16 $\mathrm{m}$, one gets good site if age is $35-45$ years, medium site if age is $45-65$ years, and poor site if age is $65-100$ years.

Because the concept of site-index classification followed by the photo interpreters is invalid, I do not find any reason to comment on the 76-percent accuracy in classifying some stands of the inventory in the study area.

Those who wish to apply the procedures proposed by the authors should be aware of the above points.

\section{I.S. Alemdag}

\section{The Editor:}

I regard the procedures described in the report (For. Chron. 57 (6): 265-266) as an initial attempt to produce a useable, nation-wide site classification system.

To improve the accuracy of the system, other factors such as tree species and management intensity must be accounted for. The question is, how does one balance the increased accuracy against the cost of obtaining the addi- tional data?

Dr. Alemdag has quite clearly shown that tree species has a significant influence on site index. Since little additional cost is associated with including this factor in the system, I am in favour of doing so - but how?

One possibility is to develop a "subjective" classification system (e.g., good/medium/poor) and define each of these classes in terms of site index and species. For example, class "medium" would include SI 15-20 for jack pine, 10-15 for white pine, and 5-10 for black spruce.

While I appreciate and concur with Dr. Alemdag's comments on the above matter, I don't understand how he got the impression that only height was used by the photo interpreters to estimate site index. In making their assessment, the interpreters used all available information from the air photos, including estimates of stand height and age, species group, topography, soils, aspect and slope. This information they integrated and used with photo interpretation keys to estimate the site index class. As is often stated, photo interpretation is an art as much as a science and the accuracy of classification depends to a large extent on the experience of the interpreter.

G.M. Bonnor

\title{
1981 Activity on Improved Forest Management in Canada: A Report to the Canadian Institute of Forestry
}

\section{Introduction}

This update on the above subject was request by CIF past president B. Devitt; the original overview of 1979-1980 activities was presented to past president J.H.G. Smith on September 29, 1980. This update overlaps the years 1980 and 1981.

Several important developments occurred in 1980 and 1981; these events were the Banff Conference (September 10-11) on Canada's Forests: Transition to Management; preparation of a discussion paper on A Forest Sector Strategy for Canada for the October 1, meeting of The Canadian Council of Resource and Environment Ministers; the October 1981 national meeting of the Canadian Institute of Forestry in Halifax on the theme Forest Renewal and Tending; Canadian Pulp and Paper Association report on accomplishments and expenditures in 1980 by member companies.

The events and reports are expanded in the following details.

\section{Banff Conference: Canada's Forest: Transistion to Management}

Held in the Banff Centre, this conference involved 60 senior members of government, organized labour, industry and universities for two days of intensive opinion presentations and workshops. (Weather was beautiful and scenerv was conducive to thoughts of forests.) Co-Chairman were Dr. F. Kenneth Hare and Mr. Adam H. Zimmerman.

The conference developed an Agenda for Action defining
What Should Be Done and Who Should Do It.

To the question of What, the delegates developed a consensus on the need for major reinvestment in forest management in Canada this reinvestment should focus on four areas, namely silviculture, forest protection against fire, insects and disease, research, and education.

Silviculture expenditures need to rise to at least $\$ 600$ million annually, from a current investment of $\$ 250$ million.

Forest protection spending needs to double from $\$ 250$ annually to $\$ 500$ million. Improvements involve better road access to the forests, quicker attack on fire, insects and disease, better pesticides and better procedures for testing and registering such pesticides.

It was recognized that the Who should do it question involved all agencies benefitting from the forest resourceowners of the forest land base, both levels of senior governments, and the forest industry. Basic responsibility for new, increased investment involved the landowners, the provincial governments and private entities. Their responsibility involved planning management objectives and performance standards, intensive forest management, and protection from fire and insects. Industrial users would be additionally responsible for seedling supply and genetic improvement of the commercial species, planting, forest management, harvesting and environmental impact, and some silvicultural research.

The federal government should accept responsibility in major research and some aspects of forestry education, in appropriate tax structures and budget commitments to forestry, in improved and priority statistical and public information apparatus, and in increased assistance to landowners for silviculture during the transition period leading 
to full forest management.

Support responsibility should be accepted by universities and technical schools to strengthen faculties and curriculum to develop standards of excellence, to double graduation of good professionals, and to foster innovative contracted or grant-supported forest research.

This conference also highlighted the need for a common voice, and a strong and consistent voice, to represent the concerns and consensus of the forest industries. A Canadian Forestry Council was proposed as a first step in filling this need. Eventually a broader forestry forum might be considered to involve also senior governments, trade unions, and forestry schools.

The full text summary of this Conference can be obtained from The Banff Centre, School of Management, Box 1020, Banff, AB. TOL OCO.

\section{A Forest Sector Strategy for Canada}

This 26-page document, (plus appendices) was presented by the sponsoring minister, The Honourable John Roberts, as a discussion paper to the meeting of the Canadian Council of Resource and Environment Ministers on October 1, 1981.

The strategy paper is an excellent overview of the current forestry situation in Canada respecting resource, forestry sector dimensions, current major issues, and specific constraints on development.

The elements of strategy are carefully detailed respecting historical federal forestry policy, market opportunities andstrategy, wood supply and means to augment supply, and strategy of supply, needs of research and development, human resource needs and the other components of resource data base, energy from biomass, industry structure and ownership, capital investment, transportation, regional and northern development, native land claims, international forestry role, and constitutional issues.

Alternative strategies are examined. Program evaluation criteria are proposed.

The appendices tabulate the statistics of forest land area in Canada, allowable annual cuts, forest industries including logging, wood industries and paper and allied industries, employment, wood products production, exports and trade balance, corporate profits, capital expenditures by industry, public revenue from forest industry, and public expenditures on forest management.

Extracts from this paper tell us that the allowable annual cuts of all commercial species in Canada have reduced dramatically in the last five years. The reduction in softwood species is about $20 \%$, while hardwood reduction is close to $35 \%$. Softwood species account for $94 \%$ of harvest and represent the most critical supply problems.

Provincially, the expose of AAC of softwood situations is more dramatic.

Newfoundland's reduction in allowable cut could represent $20 \%$ due to spruce budworm devastation and age class structure imbalance.

Nova Scotia reduction is about $15 \%$ below harvest due to spruce budworm; New Brunswick emulates Nova Scotia with its AAC reduction because of budworm losses and forest renewal neglect. Prince Edward Island concludes that the sawlog supply is heavily overcommitted.

Quebec has an indicated AAC oversupply of $25 \%$ over harvest but the hypothetical reserve is largely in uninhabited forest areas. Ontario's situation is similar to Quebec but reductions in calculated AAC's are contemplated due to budworm and fire losses, land withdrawals, and regeneration activity neglect.

Manitoba has a large AAC surplus which is unattractive for development due to remoteness, low volume per hectare and high extraction cost. The timber harvest in Saskatchewan is close to AAC, sawmills and plywood capacity is extended beyond the sustainable limits of supply. Fire losses continue to worsen the situation.

Alberta has the most promising excess AAC supply potential.

British Columbia completed an exhaustive forest and range analysis in 1980 which concluded that serious wood supply problems existed in the future for some regions.

The Yukon and Northwest Territories have a large surplus AAC but remoteness, lack of access, markets, and price of product are limiting factors to exploitation.

The meeting of the Canadian Council of Resource and Environment Minister on October 1, 1981, based on the discussion paper presented by Minister Roberts, resulted in release of an Information Communique on October 1, 1981.

This release stated: (quote verbatim)

The Canadian Council of Resource and Environment Ministers (CCREM) agreed to initiatives in Forestry at a meeting here (Ottawa) today chaired by federal Enviroment Minister John Roberts.

As a follow-up to the Forestry Imperatives report adopted in 1980 , the provinces agreed to prepare forest renewal objectives along with costs to accomplish the work with the view of sharing these costs between the forest industry and the federal and provincial governmentrs in an equitable manner.

The Council agreed that a much higher level of funding is required from governments and industry than is currently available or committed.

A proposal for an expanded forest fire research and coordinated training program was also endorsed at the twoday meeting of federal and provincial resource and environment ministers. A federal-provincial national fire information centre will permit effective interregional and interprovincial sharing of manpower and fire fighting resources in emergency situations.

Forest protection operations in the Provinces as well as the Northwest Territories and the Yukon periodically encounter unpredictable major crises such as the 1980 and 1981 fire seasons, when losses surpassed all expectations and communication and more effective sharing of scarce resources at the national level would have been beneficial.

Ministers also agreed to explore the possibility of federalprovincial co-ordination and expansion of forest fire fighting equipment and aircraft. One constraint to efficient fire control has been overall lack of major suppression equipment, especially bombing aircraft, combined with the impossibility of each province acquiring a sufficient reserve of equipment to respond to periodic crises.

An Intergovernmental Task Force will be set up to evaluate field testing and registration of pesticides considered essential for forest management.

The Council also agreed on the need for a national forum to bring together governments, industry, forest labour and academics to examine forestry issues and develop appropriate strategies for the forest sector. (End of release).

This commitment by CCREM would indicate a desire to improve forest management including forest protection in Canada. It fulfills, in large measure, the recommendations of the Banff Conference.

\section{Private Expenditures on Forest Management in 1980 by CPPA Member Companies}

This report information was published by the Woodlands Section of CPPA on February 26, 1982, as Woodlands Circular 38/82. Table 1 shows the details of net expenditures by reporting member companies in 1980, and also indicates the percentage of government support recovered by companies, to their net spending.

Table 2 compares these 1980 net expenditures by provinces, to 1979 and 1978 spendings. 
Total expenditures on forest management in 1980 declined from 1979 levels; spending on silviculture activity only increased $72 \%$ over 1979 . All provinces implemented higher private investment in silviculture in 1980, but there was a decline in total spending in the provinces of New Brunswick, Quebec, Ontario, Saskatchewan and British Columbia.

Private industry cost recoveries from government, for forest management in 1980, amounted to $\$ 69266$ million; this represented 50.3 percent of net private cost.

General Development Agreements were signed in 1974 by the Department of Regional Economic Expansion of the Federal Government and all the provinces except Prince Edward Island; the Yukon and the Northwest Territories signed agreements in 1977 and 1979 respectively. These grants allow DREE to co-operate with other federal government departments whose programs have a significant impact on regional economies, the provincial and local governments, and the private sector.

It is interesting to look at these agreement allocations by provinces and the committed amounts to forestry including the 1979-80 expenditure, as they have a relationship to government support to private industry spending on forest management. This overview of relationship is shown in Table 3.

The indicators of this data presentation in Table 3 are that in general government support to the private sector for forest management exceeds federal support to the provinces, under the General Development Agreements (GDA's) coupled with subsidiary agreements. The indicators as a generality are distorted and must be observed on a province basis.

The provinces of British Columbia, Alberta, Saskatchewan, Manitoba, and Ontario only supported forest management in 1980 by the private sector to an amount in excess of indicated federal grants; this indicated excess support was:

$\begin{array}{lr}\text { British Columbia } & \$ 49505000 \\ \text { Alberta } & 825000 \\ \text { Saskatchewan } & 95000 \\ \text { Manitoba } & 477000 \\ \text { Ontario } & 449000 \\ \text { Total excess } & \$ 51351000\end{array}$

The provinces of Quebec, New Brunswick, Nova Scotia and Newfoundland received federal grants support for forestry in 1979-80, estimated, that are far in excess of the support they tendered to the private sector, of CPPA member companies, for forest management. This provincial situation indicates the following overage support federally, by provinces:

$\begin{array}{lr}\text { Quebec } & \$ 41978000 \\ \text { New Brunswick } & 8127000 \\ \text { Nova Scotia } & 2771000 \\ \text { Total federal support overage } & \$ 56313000\end{array}$

Table 3 data can only be treated as indicators of financial arrangements between the federal government and the provinces, and between the provinces and the private sector. There is a need for better data sources to understand the relationship between federal, provincial and private sector support of forest management in Canada. This need can be illustrated by an example of one province only; this illustration is chosen since the national ClF meeting in 1981 in Halifax supported resolution 81.6 relating to continuing increased funding by both the Federal and Nova Scotia governments for intensive forest management, through appropriate financial arrangements.

The reported 1980 expenditures on forest management by CPPA member companies in Nova Scotia was

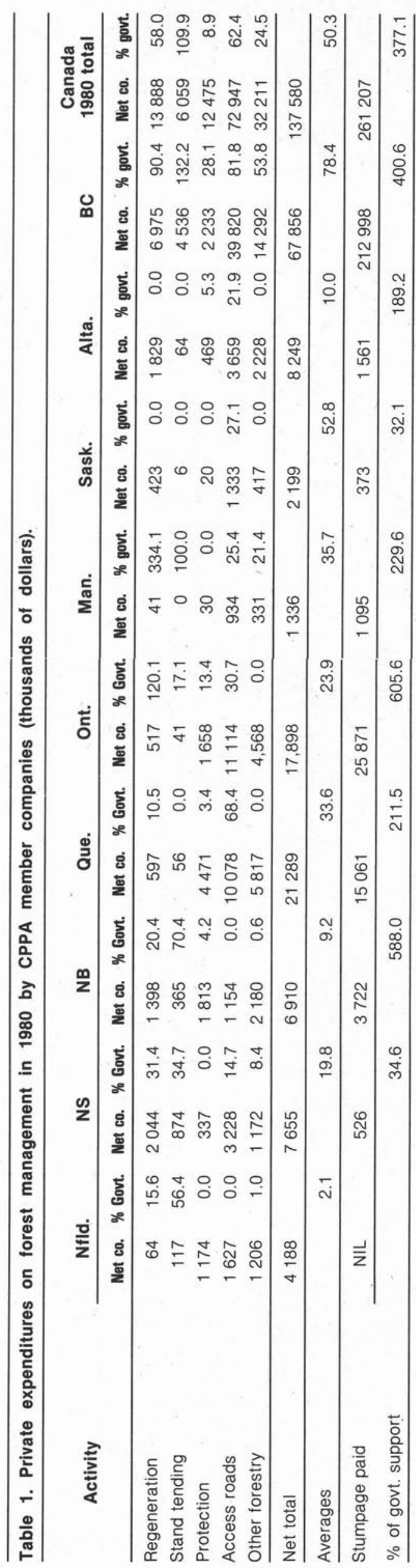


Table 2. CPPA member companies 1980 net expenditures on forest management comparison.

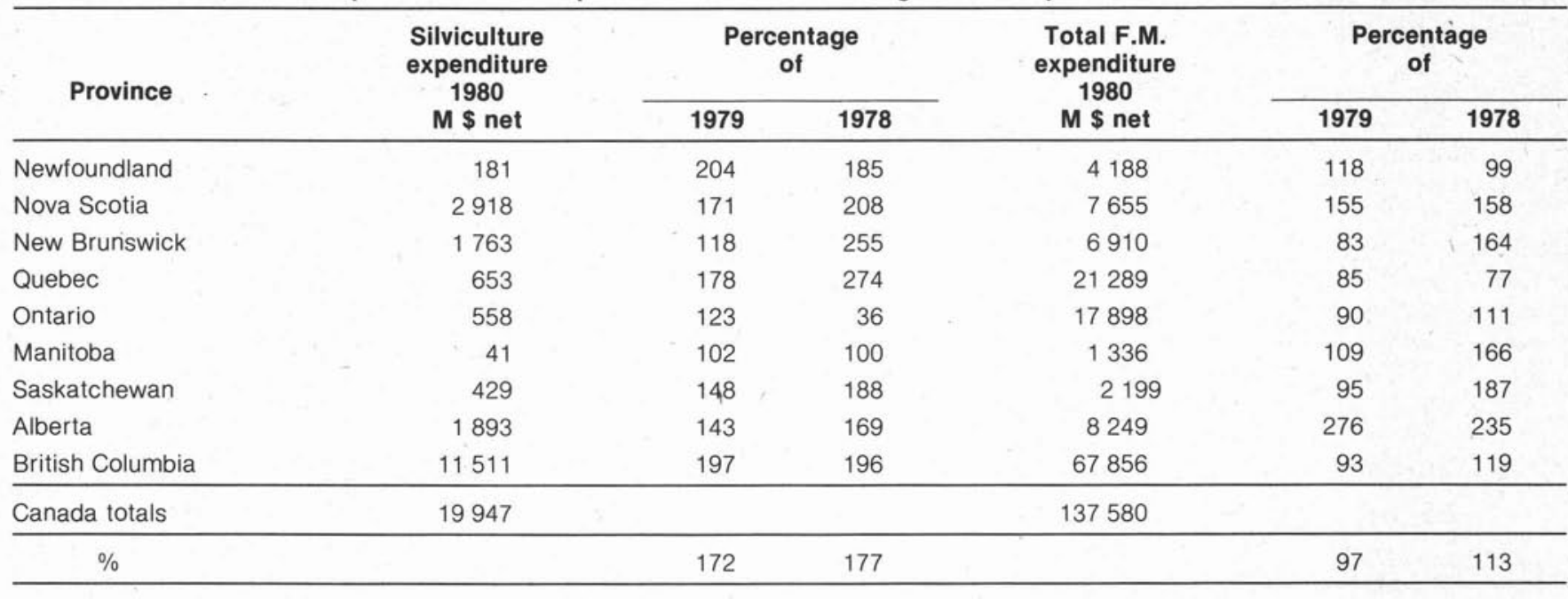

Table 3. General development agreement relation to govt. F.M. support.

\begin{tabular}{|c|c|c|c|c|}
\hline Province & \multicolumn{3}{|c|}{ DREE agreement commitment - $\$$ Fed. } & $\begin{array}{c}1980 \text { govt. support } \\
\text { for forest } \\
\text { management - } \$\end{array}$ \\
\hline Nova Scotia & 327751000 & 36142000 & 4289000 & 1518000 \\
\hline New Brunswick & 346703000 & 58903000 & 8760000 & 633000 \\
\hline Manitoba & 192697000 & NONE & NONE & 477000 \\
\hline Saskachewan & 213810000 & 12000000 & 1066000 & 1161000 \\
\hline Alberta & 73212000 & NONE & NONE & 825000 \\
\hline British Columbia & 149500000 & 25000000 & 3665000 & 53170000 \\
\hline Totals & 2813198000 & 387205000 & 49678000 & 69266000 \\
\hline
\end{tabular}

(Source: The National Finances, 1980-81, pages 182-184. CPPA Circular 38/82)

$\$ 7655000$ net; access roads costs were $\$ 3228000$ of this net total, and forestry costs including protection were $\$ 4427000$. Government support contributions totalled $\$ 1518000$; access roads were supported by $\$ 475000$ of government funding, and forestry including protection realized support of $\$ 1043000$.

The General Development Agreements - subsidiary agreements, respecting forestry, pertaining to Nova Scotia, committed the following amounts for five years during the period 1977-1982.

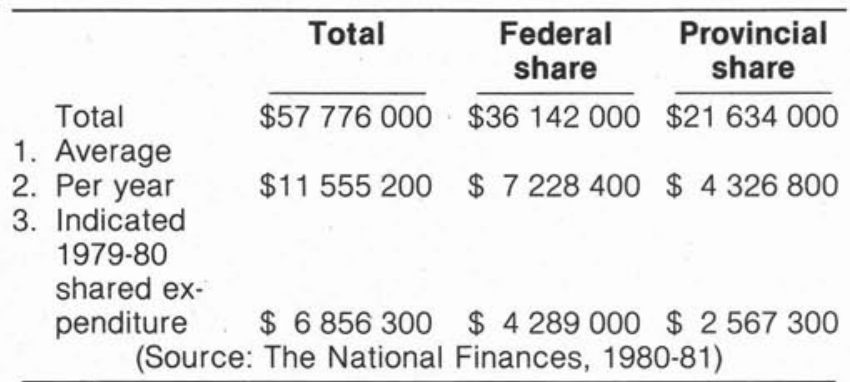

The provincial government contributed $\$ 1518000$ to private support of forest management in 1980 . This is $22 \%$ of the indicated provincial expenditure (1979-80) under subsidiary agreement with the federal government. The indicated balance of forestry expenditure of $\$ 5338300$ is then inferred to have been spent on public land forestry.
This situation is suggestively imbalanced, if inference data is indicative, since private forest land represents 76 percent of the total forest land in Nova Scotia. One might suggest that government support to the private sector might be more realistic if the yearly contribution approximated $\$ 5000000$. Sadly, concise data is not available to allow check of these inferences and judgements (nor was it tendered in support of resolution 81.6 in Halifax at our national CIF meeting).

\section{Federal Department of the Environment}

The Canadian Forestry Service operates under the umbrella of this department. Its 1980-81 budget estimates are $\$ 719.3$ million. The estimates allocated to the forestry branch are $\$ 47.4$ million, of which $\$ 39.6$ million is for operations and $\$ 3.8$ million for capital expenditures.

Forintek Canada Corporation will receive \$2.3 million; the federal government has contracted work by Forintek valued at $\$ 4.6$ million per year for five years.

The Forest Engineering Research Institute of Canada will receive $\$ 1.0$ million operating allocation and $\$ 320000$ for research and use demonstration projects on biomass harvesting.

Grants of $\$ 292000$ will be allocated to universities for research.

The Canadian Forestry Association has been assigned a grant of $\$ 50000$.

The Canadian Forestry Service will receive $\$ 35.6$ million operating budget and $\$ 3.8$ million capital funds, for opera- 
tion of its for (4) research centres at St. John's Quebec City, Sault Ste. Marie, and Victoria (plus Edmonton).

(Source: The National Finances, 1980-81, page 217)

\section{Economic Situation 1981-82}

The economic situation of the forest industry in Canada in late 1981 and early 1982 is well understood and publicized. Shut-downs of manufacturing plants and layoffs of employees were common; depressed housing construction in the USA and Canada dramatically decreased lumber sales, and general reduced business activity depressed pulp and paper sales.

At March 27, 1982, layoffs of sawmill workers from BC to Quebec totalled 14471 people; some 31000 forest workers were unemployed, and no layoffs were associated with normal seasonal work closures. Production curtailments were averaging $35 \%$

1981 values of lumber production were $\$ 2913192000$ Canadian, down by $10.7 \%$ from 1980 sales of $\$ 3261192000$. Pulp and paper shipments in 1981 were down $2.5 \%$ from 1980 .

The International Trade Commission (ITC) of the United States held hearings in March, 1982, in Portland, Oregon, on charges, originated by Senator Packwood, that Canada was dumping lumber into the US. The Board of Inquiry must submit a report to the US Senate by April 19, 1982. The Board heard submissions by representatives of the Canadian lumber industry and they visited operations and offices of the industry in British Columbia to make enquiries and to familiarize themselves with BC lumber production, costs and stumpage implications. An unfavourable opinion on this situation, by the Board, could precipitate legislative action by the US government to control or penalize exports of lumber by the Canadian industry to the US.

In 1981, these exports amounted to 9.033 billion foot board measure and the export value was $\$ 1.379$ billion dollars.

\section{Voices to Improvement in Canadian Forest Management}

The activities of the various forestry sector agencies are important to the achievement of improved forest management in Canada. Many important individuals are cognizant of the need, and are expressing their ideas and opinions in a rising crescendo across Canada. We should recognize these individuals and support them in a continuing crusade to achieve the common objective.

Mr. Adam Zimmerman, executive vice-president of Noranda Mines Ltd., has provided exemplary leadership in the crusade. He has co-chaired both the Forestry Congress in Toronto in 1980, and the Banff Congress in 1981. His recent speech to the 74th annual meeting of the Canadian Lumberman's Association (see March, 1982, Canadian Forest Industries) was a continuation of this crusade. He reemphasized the need for unified representation of the forest industries in Canada, a need which was advocated at the Banff Congress in 1981. This representation is a broadlybased group composed of forest industry interests which could relate to other groups and to governments, and to the general public. Founding members could include the various provincial forest industry associations, the Canadian Pulp \& Paper Association, Council of Forest Industries of BC, Canadian Lumberman's Association, etc. The objectives of the organization would be to provide information to governments and to the public on the industry and on the use and management of the forest lands of Canada. This narrow mandate is important to give focus to activities.

The Honourable John Roberts has given stimulus and em. phasis to improvements in forest management by his introduction of the discussion paper, A Forest Sector Strategy for Canada, to the federal government caucus committee for approval, and its sponsorship at the October, 1981, meeting of the Canadian Council of Resource and Environment Ministers. He has also asked the Canadian Forestry Advisory Council for its recommendation of a suitable format for a national body to speak for the forest industry. $\mathrm{He}$ has recently signed the first federal-provincial Memorandum of Understanding, concerning the co-ordination of forests research, with BC Minister of Forests, the Honourable Tom Waterland.

Mr. Les Reed, Assistant Deputy Minister of the Department of the Environment has been instrumental in generating action through many agencies in improving the forest management situation. He has been an active organizer and participant in the 1980 and 1981 Forestry Congresses at Toronto and Banff. He provided the guidance in preparation of the discussion paper A Forest Sector Strategy for Canada, and recently installed a reorganization of the Canadian Forestry Service.

The Association of University Schools of Canada, represented by the universities of New Brunswick, Laval (Quebec), Toronto, Lakehead (Thunder Bay, Ont.) Alberta, and British Columbia, has been active in determining potential solutions to the problem of increasing enrollment to meet Canada's future needs for increased numbers of foresters, as well as determining approaches to provincial governments to stop the continual erosion of funding of university grants. They have also been exploring ways to encourage industry participation in their programs and in funding university research, and in upgrading industry staff foresters through industry financing.

The deans of the university schools of forestry deserve recognition for their activities in educational improvement. They are: J.W. Ker (now G. Baskerville - UNB), Y. Hardy M. Lortie (Laval), V. Nordin (Toronto), A.J. Kayll (Lakehead), P.J. Murphy (Alta.), J. Gardner (BC).

The Honourable A. McEachen in his November, 1981, budget presentation made a commitment in his tabled document entitled Economic Development for Canada in the 1980 's, that his government will be continuing consultations with the provinces in the coming year (note time commitment) concerning measures to enhance the longer term performance of the forest based industries. He further stated that if Canada is to capitalize on the international market opportunities open to its leading sector, it must ensure the continued availability of competitive supplies of good quality timber through reforestation, other forest management practices and better utilization of the existing resource. To achieve this result, there must be an increase in forest research and development, both conducted by and supported by the federal government in the areas of production, basic research, harvesting and forest products.

At long last we have a powerful, political voice of commitment to the crusade.

\section{Final Comment:}

It is encouraging to report on continued progress in forest management in Canada. All available data in this report, explicit or inferred, does not fully support this feeling of encouragement; in some provinces, I am hesitant to acknowledge that a forward thrust is evident.

There is a need to reiterate my September 29, 1980, request to the National CIF executive that section representatives be responsible for reporting yearly to the institute body on provincial statistics related to forest management activities and expenditures by both industry and government. This base data can be used for national reporting by the CIF. 